\title{
Endometriosis in Umbilical Hernia
}

\section{Saud Al Omani ${ }^{1 *}$ and Nouf Yassin ${ }^{2}$}

${ }^{1}$ Department of General Surgery, Prince Sultan Military Medical City, Riyadh, Saudi Arabia

${ }^{2}$ General Surgery Senior Registrar, Prince Sultan Military Medical City, Riyadh, Saudi Arabia

*Corresponding Author: Saud Al Omani, Department of General Surgery, Prince Sultan Military Medical City, Riyadh, Saudi Arabia.

\section{Received: May 28,2020}

Published: June 26, 2020

(C) All rights are reserved by Goce Kalcev., et al.

\section{Abstract}

Endometriosis is the presence of functional endometrium tissue outside the uterus. It affects approximately $11 \%$ of the population [1]. Here we present a patient with atypical history who was found to have Extra-pelvic endometrosis in the sac of a recurrent paraumbilical hernia.

Keywords: Hernia; Endometriosis

\section{Introduction}

Endometriosis is the presence of functional endometrium tissue outside the uterus. It affects approximately $11 \%$ of the population [1].

\section{Case Report}

A 46-Years old Saudi female housewife. Known case of type II Diabetes Mellitus and Iron deficiency anemia on medications. She has a previous history of paraumbilical hernia open primary repair seventeen years ago and three Cesarean section, the last one being six years ago.

She presented to our surgical outpatient department complaining of periumbilical swelling for the past five years. It was Increasing in size with cough and straining and associated with pain around menstruation period. There was no history of vomiting and no change of bowel habits. Systemic review otherwise was unremarkable.

On local abdominal examination, there was a suprapubic transverse incision and another paraumbilical incision with an Infraumbilical $3 \times 4 \mathrm{~cm}$ swelling with no positive cough impulse and no overlying skin changes. It was mildly tender on palpation and partially reducible. No Bowel sounds audible over it. Other hernia orifices are free.

Our impression was recurrent ventral hernia and the patient was admitted and prepared for surgery. She underwent Laparoscopic exploration with adhenolysis and findings were of multiple defects ( $4 \times 5$ and $1 \times 1 \mathrm{~cm}$ ) with a mass found at the root of the umbilical which underwent full excision and sent for histopathology along with the hernial sac and the umbilicus. We proceeded with Laparoscopic Assisted repair of the hernia with mesh placement.

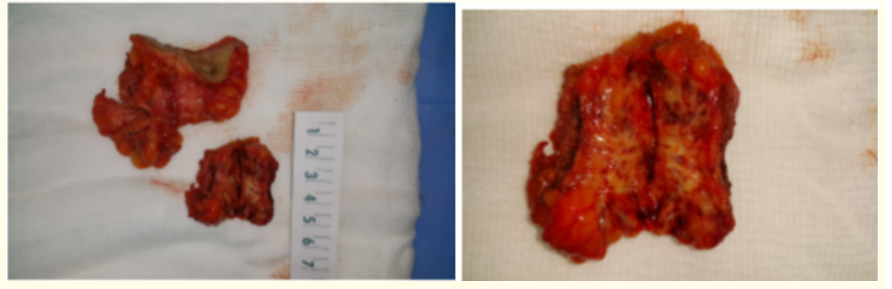

Figure 1

She was admitted for two days with unremarkable postoperative recovery and discharged in good condition. The patient was seen in the clinic two weeks later. She was doing well and the pain has improved significantly. The wound was healing nicely and all sutures were removed.

The histopathology report of hernia content came to be mature adipose tissue. The umbilical with periumbilical mass came to be consistent with Endometriosis and negative for any malignancies.

\section{Discussion}

A hernia is defined as a protrusion of an abdominal content through a defect. Abdominal wall hernias are one of the most common surgical pathologies operated by surgeons around the world. 
Incisional hernias are secondary to prior surgery and occur at the origin of surgical incision, drain site or a trocar site [2]. Surgical repair can be achieved by open repair, laparoscopic repair or laparoscopic Assisted repair. The use of prosthetic mesh is a surgeons choice depending on many factors.

Endometriosis is the presence of endometrial tissue implanted outside the uterus which could be intrapelvic like the ovaries, vagina, rectum or bladder, distal ureter or extrapelvic including bowel, lungs, brain and umbilical. It affects $10-15 \%$ of females of reproductive age [3] and 25 - 40\% in Infertile women [4]. Umbilical endometriosis is very rare accounting for $0.5 \%$ cases of extrapelvic endometriosis [5].

The exact pathogenesis of umbilical endometriosis is not fully known. Primary umbilical endometriosis could be explained by migration of endometrial cell through the abdominal cavity, lymphatic system or patent umbilical urachus [6]. Secondary umbilical endometriosis could be iatrogenic dissemination of the endometrial tissue after surgery like cesarean section, laparoscopic surgery or even episiotomy $[7,8]$. The implanted tissue will be affected by estrogen and proliferate at the same time as the normal endometrial tissue in the uterus and bleed at the time of menstrual period.

Reaching the proper diagnosis of umbilical endometriosis is crucial because $50 \%$ of patients will have concurrent pelvic endometriosis which can lead to infertility in $30-50 \%$ [9]. Diagnosis could be challenging due to atypical non specific presentation in most cases. The definite diagnosis is usually made after histopathological examination. Endometriosis should be considered in all female of reproductive age or post menopausal, with or without history of cesarean section, who have periumbilical pain which could by cyclic especially in the presence of an abnormal mass. Magnetic Resonance Imaging is the best modality for evaluating extrapelvic endometriosis [10]. Ultrasound guided Fine Needle Aspiration (FNA) is usually recommended for definite diagnosis and to rule out malignancy in order to strategically plan the proper surgical intervention especially if the excision area is large which will require synthetic mesh use or possible abdominal wall reconstruction.

The risk of cancer transformation in umbilical endometriosis is rare and only two cases were officially reported. The first case was reported in 1972 by Lauslahti where the patient had malignant umbilical endometriosis in the form of endocarcinoma [11]. The second case was reported by Obata., et al. with umbilical endometriosis clear cell carcinoma [12].

Initial therapeutic option for abdominal wall endometriosis could be pharmacologic therapy with non- steroidal anti-inflammatory drugs or hormonal agents such as progesterone with low success rate and temporary relieve of symptoms. Surgical excision in the form of wide local excision offers the best therapeutic option with lower recurrence rate [13]. Hysterectomy to relieve the pain is usually the last resort.

\section{Conclusion}

Extrapelvic abdominal wall endometriosis reported in umbilical hernias is a rare condition that is most commonly but not exclusively reported in females with previous cesarean section. Diagnosis could be challenging as the pain is usually non-cyclic and a palpable mass is not always present.

\section{Bibliography}

1. American Womens Health.

2. Cameron $12^{\text {th }}$ edition.

3. Mehedintu C., et al. "Endometriosis still a challenge". Journal of Medicine and Life 157.3 (2014): 349-357.

4. Ozkan S., et al. "Endometriosis and infertility: epidemiology and evidence-based treatments". Annals of the New York Academy of Sciences 27 (2008): 92-100.

5. International Journal of Medicine: Endometriosis news.

6. EI Efremidou., et al. "Primary umbilical endometrioma: a rare case of spontaneous abdominal wall endometriosis". International Journal of General Medicine 5 (2012): 999-1002.

7. A Fancellu., et al. "Primary umbilical endometriosis. Case report and discussion on management options". International Journal of Surgery Case Reports 4 (2013): 1145-1148.

8. R Victory., et al. "Villar's nodule: a case report and systematic literature review of endometriosis externa of the umbilicus". Journal of Minimally Invasive Gynecology 14 (2007): 23-32.

9. Counsellor VS. "Endometriosis. A clinical and surgical review". American Journal of Obstetrics and Gynecology 36 (1938): 877.

10. Yu CY., et al. "MR appearance of umbilical endometriosis". Journal of Computer Assisted Tomography 18.2 (1994): 269-271.

11. K Lauslahti. "Malignant external endometriosis. A case of adenocarcinoma of umbilical endometriosis". Acta Pathologica et Microbiologica Scandinavica 233 (1972): 98-102.

12. K Obata., et al. "Clear cell adenocarcinoma arising from umbilical endometriosis". The Journal of Obstetrics and Gynaecology Research 39 (2013): 455-461. 
13. Seydel AS., et al. "Extrapelvic endometriosis: diagnosis and treatment”. American Journal of Surgery 171 (1996): 239-241.

\section{Assets from publication with us}

- Prompt Acknowledgement after receiving the article

- Thorough Double blinded peer review

- Rapid Publication

- Issue of Publication Certificate

- High visibility of your Published work

Website: www.actascientific.com/

Submit Article: www.actascientific.com/submission.php

Email us: editor@actascientific.com

Contact us: +919182824667 